Immunol Allergy Clin North Am. 2019 February ; 39(1): 63-79. doi:10.1016/j.iac.2018.08.008.

\title{
Early-Onset Inflammatory Bowel Disease
}

\author{
Judith R. Kelsen, MDa ${ }^{\mathrm{a}}$, Pierre Russo, MD $^{\mathrm{b}}$, Kathleen E. Sullivan, MD, PhDc, ${ }^{*}$ \\ aDivision of Gastroenterology, Hepatology and Nutrition, 3401 Civic Center Boulevard, \\ Philadelphia, PA 19104, USA; \\ bDepartment of Pathology, Division of Allergy Immunology, The Children's Hospital of \\ Philadelphia, ARC 1216-I, 3615 Civic Center Boulevard, Philadelphia, PA 19104, USA; \\ 'Division of Allergy Immunology, The Children's Hospital of Philadelphia, 3615 Civic Center \\ Boulevard, Philadelphia, PA 19104, USA
}

\section{Keywords \\ VEO-IBD; Primary immunodeficiencies; Inflammation; Monogenic}

\section{INTRODUCTION}

Inflammatory bowel disease (IBD) is a complex disorder associated with a dysregulated immune response to environmental triggers in the genetically susceptible host. The frequency of this condition is increasing dramatically around the world, with the greatest increases in developing countries and young children. ${ }^{1-3}$ The etiopathogenesis of the disorder is understood very poorly and the reasons for the increase in frequency in industrialized countries are probably multifactorial. Proposed mechanisms driving the increased incidence of IBD include increased antibiotic use, decreasing exposure to parasites and other infections, changes in diet, including the adoption of prepared foods that include emulsifiers and surfactants, all of which contribute to alterations in the gut microbiome. ${ }^{4}$ Although IBD in young children has always been uncommon, this group is now experiencing the greatest increase in incidence. ${ }^{3}$ In previous years, immunologists called on to see a very young child with IBD could be nearly certain that there would be an immunodeficiency. Today, with the rising incidence, it is more difficult to identify children with an inborn error of immunity who are presenting with IBD versus those children who have more typical polygenic inheritance with an exceptionally early onset of disease. This group of children with early-onset IBD, regardless of whether there is an inborn error of immunity, suffers from very high morbidity and a high burden of disease. This review is focused on understanding the immunologic contributors to IBD, the epidemiology, and the role of the immunologist in the diagnosis and management of patients with very early onset IBD (VEO-IBD).

*Corresponding author. sullivank@email.chop.edu.

The US Immunodeficiency Network (USIDNET) data were supplied by the following contributors who provided at least $1 \%$ of the data for analysis: Ramsay Fuleihan, Elizabeth Garabedian, Charlotte Cunningham-Rundles, Rebecca Marsh, Hans D. Ochs, Avni Joshi, Daniel Suez, Elizabeth A. Secord, John Routes, Javeed Akhter, Francisco A. Bonilla, Jennifer Puck, Niraj Patel, Rebecca

Buckley, Patricia Lugar, Burcin Uygungil, Gary Kleiner, and Morton J. Cowan. 
The gastrointestinal tract is the largest immune organ in the body. Thus, it is no surprise that people with known immune deficiencies are at increased risk of developing IBD (Fig. 1). Classic IBD, as well as autoimmune enteropathy occur with high frequency in children with inborn errors of immunity, and studies have demonstrated that patients with significant enteropathy both have a shortened life expectancy and profoundly worse quality of life in common variable immunodeficiency. ${ }^{5}$ There are clues to the immunologic underpinning of polygenic IBD from genome-wide association studies (GWAS). There is a strong association between major histocompatibility complex (MHC) haplotypes and IBD across multiple large GWAS. ${ }^{6-8}$ Additional genes implicated in these large studies include those relevant for immunologic function as well as those related to barrier function of the gastrointestinal tract. ${ }^{9}$ Other evidence supporting a key immunologic role in all types of IBD include gene expression arrays that demonstrate disordered function of the immune system. ${ }^{10,11}$ This review focuses on those children with inborn errors of immunity that drive the development of VEO-IBD. These children provide key insights into the mechanisms of disease in IBD. Our understanding today of who develops IBD, why they develop IBD, and which type of therapy is most likely to yield the perfect balance between control of disease and minimizing adverse events is clearly better than in the past; however, it remains remarkably difficult to counsel families regarding prognosis when the onset of IBD is early in life. It is worth reflecting on the progress we have made in understanding inflammation to provide context for our current understanding of IBD.

\section{THE ANCIENT UNDERSTANDING OF INFLAMMATION}

Hippocrates believed that inflammation was integral to healing and introduced the word edema to the medical community. Indeed, inflammation leads to secretion of angiogenic and fibroblast growth factors regulating healing. ${ }^{12}$ Thus, inflammation is not intrinsically deleterious. It serves a key role in host defense and promotes healing in physiologic settings. The key concepts of inflammation were first articulated by Aulus Celsus, 500 years after Hippocrates, when redness, warmth, swelling, and pain were articulated as manifestations of inflammation. Vasodilation accounts for the redness and warmth associated with inflammation and vascular leak accounts for the swelling or edema. When Antony van Leeuwenhoek improved the lens sufficiently to see individual cells, one of his first targets was to describe microcirculation changes related to inflammation. Dutrochet saw that white cells accumulate in inflammation in 1824. These studies paved the way to consider an integrated view of circulation as a pipeline for white cell delivery. Thus, the ancient understanding of inflammation evolved to a basic mechanistic understanding by the mid-1800s. Still today, we use the character of the invading cells to define the type of inflammation we seek to treat.

If inflammation represents an ancient concept that has been refined over the years, autoimmunity represents a much more recent concept. The overall concept of immunity sputtered through history, beginning with Thucydides' description of the plague of Athens rendering sufferers immune to a second attack. In 1900, Paul Ehrlich stated flatly that antibodies could not be generated to self, and it was only in the 1950s that autoantibodies were clearly demonstrated in human disease states. IBD is traditionally described as an 
inflammatory disease; however, therapy with T-cell-directed agents has achieved new prominence, supporting a model in which IBD is driven by true autoimmunity.

Today, we continue to characterize the inflammatory cell infiltrate as a strategy to inform on our understanding (see later in this article). The most common biologic therapy, use of a tumor necrosis factor (TNF) inhibitor, is predicated on the common observation that neutrophils are the most common infiltrating cell type in colitis and that inhibition of TNF diminishes their migration out of the vascular space and into the tissue. ${ }^{13}$ We treat the general elements of inflammation using aspirin derivatives that dampen leukotriene and prostaglandin pathways, a concept that Celsus described and was exploited by Imhotep in ancient Egypt using willow bark. ${ }^{14,15}$

\section{TYPES OF INFLAMMATORY BOWEL DISEASE}

Textbooks often emphasize the distinction between Crohn disease and ulcerative colitis. Indeed, there are important clinical differences. The key differences are highlighted in Table 1. Crohn disease is characterized by transmural pleomorphic inflammation and the deep involvement leads to fistulas and abscesses. Granulomas are often seen and any part of the intestine can be involved. In addition, Crohn disease can involve the entire gastrointestinal tract, including perianal disease. In ulcerative colitis, the inflammation is limited to the colon and is most often characterized by a neutrophilic inflammation. Both can be associated with extraintestinal features and both have significant complications. Gene expression arrays have identified differences and commonalities in the 2 types of IBD. ${ }^{11,}{ }^{16-18}$ Indeterminate IBD or IBD-undifferentiated (IBD-U) are terms used to classify patients with clear evidence of IBD but for whom neither Crohn disease nor ulcerative colitis can be confidently diagnosed. This class is much more common in children than in adults, in whom $5 \%$ to $10 \%$ of patients with IBD are initially classified as IBD-U. ${ }^{19}$ This is particularly so for the very young children, with onset at younger than 6 years of age, known as VEO-IBD. These children can present with pancolonic disease, but over time, disease can extend to other locations. ${ }^{20-23}$

\section{Pathologic Features of Inflammatory Bowel Disease and Very Early Onset Inflammatory Bowel Disease}

There are several compelling reasons to perform endoscopy/colonoscopy in the setting of IBD or suspected $\mathrm{IBD}^{24}$ :

- $\quad$ Establishing or confirming the diagnosis of IBD

- $\quad$ Distinguishing between Crohn disease and ulcerative colitis

- Defining the extent of inflammation (critical for therapy)

- $\quad$ Evaluating for dysplasia or malignancy

- $\quad$ Monitoring efficacy of therapy

The pathologic findings may be divided by anatomic location or structural derivation and it is useful to partition the evaluation in this way. Pathology reports may use the PAID reporting system of Pattern, Activity, Interpretation, and Dysplasia and typically report the follow features: 
- Architectural features: crypt structure, surface irregularity, villi in the small bowel

- Inflammatory features: neutrophils, lymphocytes, granulomas

- $\quad$ Epithelial: Paneth cell metaplasia, mucin depletion

The normal colon is characterized by beautiful regular crypts (Fig. 2). The crypts extend from the luminal surface to the muscularis layer in regular parallel columns. Plasma cells are common in the upper third, but are infrequent or absent near the muscularis mucosa. In the cecum and ascending colon, more plasma cells are seen and they may be found throughout the lamina propria. ${ }^{24}$ Acute inflammation is described when cryptitis, crypt abscesses, and/or ulceration are seen. To diagnose IBD, chronic changes also must be observed. These include crypt distortion, crypt branching (rare branched crypts on an otherwise normal sample are acceptable), crypt atrophy, and basal plasma cell expansion (Fig. 3). Granulomas are also classified as chronic changes. Additional features of chronic changes include Paneth cell metaplasia with eosinophilic inclusions and mucin depletion. This latter finding is highly subjective but refers to the goblet cell mucin that is normally abundant in crypts. The time course of these chronic changes varies, but most are observed within a few months of onset. ${ }^{25}$ Nevertheless, it is not uncommon to observe acute changes without chronic features when biopsies are performed near the disease onset. In this setting, IBD cannot be diagnosed. ${ }^{26}$ Although chronic changes can be detected shortly after onset of symptoms, or even prior, many patients have had symptoms for several months before seeking medical attention. Thus, this practical consideration is relevant in a minority of patients.

The pathologic features more characteristic of VEO-IBD compared with older pediatric and adult-onset IBD include eosinophils in the crypts and apoptotic crypt cells (Fig. 4). These are seldom seen in adult IBD unless the disease is very active but are common in VEO-IBD. The finding of eosinophils can cause confusion with allergy or eosinophilic gastroenteridites. ${ }^{27}$ When apoptotic cells are abundant, the pathology may resemble graft versus host disease and can be associated with dyskeratosis congenita. ${ }^{28}$

Involvement of the small bowel is less well characterized in VEO-IBD but villous atrophy can be a feature. Small bowel involvement is not uncommon in Crohn disease and the pattern is a mixed inflammatory cell infiltrate. Villous blunting or atrophy is uncommon in adult IBD cohorts but is seen in as many as $20 \%$ of the VEO-IBD cohort.

\section{DIFFERENTIAL DIAGNOSIS OF INFLAMMATORY BOWEL DISEASE}

There are 2 main considerations in a previously well child, although the entire differential is considerable (Table 2). Infection is more common statistically in this age range than IBD. Tuberculosis, amebiasis, Clostridium difficile, cryptosporidia, and schistosomiasis have distinctive pathologic features recognizable on endoscopy. The most common issue is distinguishing acute infection with Campylobacter, $C$ difficile colitis, Salmonella, or Shigella from acute onset of IBD in childhood. ${ }^{25,29,30}$ Cryptitis and crypt abscesses may be features of infectious colitis (Fig. 5). Basal plasmacytosis and abnormal crypt architecture strongly favor inflammation due to infectious causes. ${ }^{24,31}$ In adults and older children, there are several mimics of IBD that should be considered but they are seldom relevant for the 
VEO-IBD population (see Table 2). The second consideration is food protein-induced enterocolitis (FPIES). Both conditions can present abruptly with bloody diarrhea. Classic acute FPIES usually occurs in an infant who exhibits repetitive vomiting, diarrhea, dehydration, and hypovolemic shock. ${ }^{32,33}$ The very acute setting with vomiting is atypical for VEO-IBD. Of more concern is the rare entity of chronic FPIES in which chronic diarrhea, anemia, and hypoalbuminemia may be seen. ${ }^{34}$ This is very typical for VEO-IBD and an additional confusion is the finding of tissue eosinophilia in both on biopsy. Chronic crypt changes are not common in FPIES; however, there are limited data on the pathologic features of chronic FPIES. ${ }^{35}$

\section{CLINICAL FEATURES OF VERY EARLY ONSET INFLAMMATORY BOWEL DISEASE}

Early-onset disease in many conditions such as systemic lupus erythematosus portends a more difficult course, whereas in others, such as Henoch Schönlein purpura, children fare better than adults. Patients with VEO-IBD, regardless of whether a monogenic cause is found, have more severe disease and more years of disease burden. Thus, they accrue damage disproportionately. Some metrics of disease severity include the higher rate of surgical intervention, higher rate of extraintestinal manifestations, and higher failure rate of TNF inhibitors. Children also exhibit growth failure probably in part due to compromised nutrition and in part due to chronic inflammation. Less commonly, chronic corticosteroids may play a role. The disease is more likely to be colonic in VEO-IBD compared with older children and adults. This is notable because some of the monogenic causes are associated with panenteric disease.

The extraintestinal features can drive the selection of therapy. As an example, the treatment in cases with sclerosing cholangitis, thought to be due to a T-cell-driven process, often uses corticosteroids, azathioprine, cyclosporine, or tacrolimus. Extraintestinal features differ somewhat between Crohn disease and ulcerative colitis in adults. The only available data have been collected in adults (Table 3). These features also are highly influenced by MHC alleles. ${ }^{36}$ Arthritis and spondyloarthropathy occur more frequently in children than adults, but there has been little effort to compare these manifestations in head-to-head comparisons of children and adults (Table 4). ${ }^{37-39}$

\section{Genetics of Inflammatory Bowel Disease}

IBD has long been recognized as having a heritable component. It is found at higher rates in Caucasian individuals, especially those with Jewish ancestry. ${ }^{40}$ The relative risk for a sibling of a patient with IBD is 13 to 26 for Crohn disease and 7 to 17 for ulcerative colitis. ${ }^{41}$ Monozygotic twin concordance rates are 30\% for Crohn disease and 15\% for ulcerative colitis. ${ }^{42-44}$ When GWASs have been performed, the MHC class II region has had a strong signal, implicating T cells in the pathophysiology. ${ }^{45}$ NOD2 (also known as CARD11) was one of the first variants to exhibit a strong association with IBD. ${ }^{46}$ The effect is limited to Crohn disease. The 3 common variants (R702W, G908R, L1007fs) all impair activation of the NOD2 signaling pathway by its biological ligand, muramyl dipeptide. ${ }^{47}$ These variants can therefore be considered to represent an immunodeficiency related to innate pattern 
recognition. A single NOD2 risk allele confers a relative risk of 2-fold to 3-fold over the general population, whereas 2 risk alleles confer a relative risk of 17 -fold. ${ }^{48,49}$ Additional genes identified by GWASs have strongly implicated the immune system in the pathogenesis of IBD. ${ }^{50}$ Cytokine pathways and autophagy gene variants have been prominent findings. 51,52 Not all loci identified in adult studies have been found in pediatric studies and vice versa; however, the pathways identified appear comparable. ${ }^{53-57}$ When whole-exome sequencing has been performed, enrichment in rare variants related to immune function have been identified. ${ }^{58,59}$ Interestingly, most of the genes implicated in the GWASs of IBD have been implicated in various other autoimmune diseases both in children and adults. ${ }^{60}$ These data suggest that compromised tolerance or immune function can impact susceptibility to autoimmunity in a general way, with the specific phenotype manifested differentially depending on environment or other genes.

IBD has been long recognized as associated with primary immunodeficiencies. In some cases, the association is very high, as for IKBKG (NF-kappa-B essential modulator [NEMO]), CYBB (chronic granulomatous disease [CGD]), and BTK (agammaglobulinemia [XLA]) deficiencies, whereas in other gene defects only a single or a few cases of IBD have been reported. In common variable immune deficiency (CVID), various autoimmune diseases, including IBD, are fairly common (see Fig. 1). Most other primary immunodeficiencies, however, are enriched for a single prominent type of autoimmune disease. Mechanisms are infrequently fully understood even in these settings with a singlegene effect. Altered signaling leading to compromised tolerance are invoked for many disorders that primarily impact lymphocyte function, whereas impaired surveillance of the enteric surface is often invoked related to innate immune defects, such as CGD. ${ }^{61,62}$ In all cases, an altered microbiome is likely to contribute to IBD susceptibility. ${ }^{63}$

A common conundrum for clinical immunologists is to determine which among the growing cohort of young children with IBD have an underlying primary immunodeficiency. The question is not simply academic. Although therapy for some patients with VEO-IBD can be straightforward, treatment can be difficult and subject to frequent failure. ${ }^{64-66}$ The therapy for those with primary immunodeficiencies can be even more difficult. ${ }^{67,68}$ Knowing the gene defect can be extremely helpful in defining the therapy (Table 5).

There is no single biomarker that cleanly segregates patients having an underlying immunodeficiency from those who do not. Instead, it is useful to think of red flags for the consideration for sequencing, which is the most ensured way to establish a diagnosis. ${ }^{68,69}$ Infantile onset is always a concern for a monogenic cause. In a key finding reported by Uhlig and colleagues, ${ }^{68}$ the earlier the onset of IBD, the more likely that there was a monogenic cause. All the patients they reported with interleukin (IL)-10 pathway, TTC7A, PLCG2, and ADAM17 defects had onset of IBD in infancy. Atypical severe combined immunodeficiency (SCID), severe dyskeratosis congenita, and IPEX cases developed IBD in childhood. These contrast with Wiskott-Aldrich syndrome, CGD, LRBA (CVID phenotype), IKBKG (NEMO), XIAP, Hermansky Pudlak syndrome, and other B-cell defects that had a very broad spread in age of onset, with some cases developing IBD in adulthood. The impact of this study cannot be overstated. Patients with primary immunodeficiencies are usually identified before adulthood, but the important implication of this study is that for many 
single-gene defects, presentation could even occur in adulthood. Indeed, studies of adult cohorts have uniformly revealed monogenic cases at a low rate. ${ }^{70-73}$ Age of onset is useful, therefore, in risk-stratifying, but there is age cutoff after which the concern for a monogenic cause is no longer valid.

If age is imperfect, what other features are useful? The pathology is another example of a useful yet imperfect predictor of a monogenic cause. Panenteric disease, villous blunting, tissue eosinophilia, and increased epithelial apoptosis are other useful data points that suggest a monogenic cause. Finally, flow cytometry is not useful in the IL-10 family of defects but can provide some supportive evidence in other cases. For the typical lymphocyte defects, inverted CD4/CD8, low T-cell counts, absent B cells, and other key findings may point to a cause. A dihydrorhodamine test for CGD should always be performed because TNF inhibitors are contraindicated in CGD. ${ }^{74}$

Finally, the clinical history and family history are very helpful in many cases. Although a positive family history is common in IBD and VEO-IBD, a family history of other conditions may point toward a single unifying explanation. The clinical history may exhibit classic infectious signs to suggest an immunodeficiency, but that is not very typical. The most helpful historic features are often other autoimmune diseases. Multiple severe autoimmune diseases support a monogenic cause. Hemophagocytic syndrome represents another notable clinical finding in the patient or in a sibling.

It may be appreciated that although we currently lack a single biomarker, armed with the knowledge of less common features that are predictive, judicious ordering of genetic testing can be pursued. Today, there are IBD gene panels and whole-exome sequencing that are reasonably cost-effective compared with the cost of continued complications and hospitalizations. Table 6 lists monogenic causes of VEO-IBD. This list does not include single cases and it is important to recognize that the landscape changes very quickly.

\section{A Strategy to Evaluate Patients with Very Early Onset Inflammatory Bowel Disease}

There is no single appropriate approach to workup of children with VEO-IBD. The community must share experiences and develop an approach that is based on evidence. Many centers are developing a joint gastroenterology-immunology approach to this patient population. This will likely yield important insights. In this spirit, this article shares 1 approach to the evaluation.

Establishing the diagnosis of IBD:

- Rule out infection with stool culture, ova, and parasite examination

- $\quad$ Fecal calprotectin (this can be low in infants with IBD)

- $\quad$ Endoscopy and colonoscopy

IBD in children with onset at age younger than 6 years: diagnostic evaluation for primary immunodeficiencies:

- $\quad$ Family history and clinical features: infections, autoimmunity, complications 
- $\quad$ Review pathology to identify atypical features

- Dihydrorhodamine test for CGD

- $\quad$ Flow cytometry to assess T/B-cell subsets and maturation

- $\quad$ Consider:

- $\quad$ Natural killer cell function

- $\quad$ IL-10 suppression assay (identifies only IL-10 receptor defects)

- Sequencing:

- Currently, whole-exome sequencing offers the greatest sensitivity when paired with copy number variation

- Many IBD sequencing panels are now offered and represent a strategy more likely to get insurance approval

Management approaches in VEO-IBD:

- $\quad$ Enteral nutrition

- Aminosalicylate derivatives (Azo-based formulations, such as balsalazide, act only in the colon; mesalamine formulations, such as Pentasa and Asacol, act in the terminal ileum and colon)

- $\quad$ Antibiotic treatment

- $\quad$ Probiotics

- $\quad$ Systemic corticosteroids (acutely)

- $\quad$ Topical steroids: budesonide (ileal release and rectal suppositories)

- 6-mercaptopurine and azathioprine (monitor for idiosyncratic reactions, seldom used in children due to risk of malignancy)

- Methotrexate (monitoring required, folate needed at higher doses)

- $\quad$ TNF inhibitors (contraindicated in CGD)

- Ustekinumab

- $\quad$ Tofacitinib (limited data)

- $\quad$ Vedolizumab

- $\quad$ Surgical diversion, colectomy

- $\quad$ Alternative options for refractory disease

- $\quad$ IL-1 blockade

- $\quad$ Rituximab

- Cyclosporine

- $\quad$ Tacrolimus 


\section{SUMMARY}

The landscape of VEO-IBD is changing in Westernized countries with decreasing age of incidence and increasing global frequency. ${ }^{3}$ For clinical immunologists, this poses a difficult conundrum. There are imperfect strategies outside of sequencing to identify patients who have VEO-IBD due to a primary immunodeficiency. Clinical features, pathologic features, and flow cytometry can define a group at higher risk for a monogenic primary immunodeficiency, but to date there is no single biomarker. Sequencing options are almost bewildering, with multiple single-gene options, gene panels, and whole-exome sequencing. In our cohort, monogenic primary immunodeficiencies have been found in $20 \%$ of those with age of onset at younger than 6 years. Among those, novel genes have been identified at a frequency of $20 \%$ in the entire set of monogenic conditions. This suggests that gene panels, while useful, are also imperfect. Whole-exome approaches that filter out novel variants will miss a significant fraction of patients. Over time, with better data and collaborative approaches, the immunology/gastroenterology community will be able to more rationally design diagnostic approaches and direct development of gene panels appropriate for this population.

\section{Disclosure Statement:}

The authors would like to acknowledge support from The Children's Hospital of Philadelphia, the Wallace Chair of Pediatrics, and K23 DK100461.

\section{REFERENCES}

1. Bach JF. The effect of infections on susceptibility to autoimmune and allergic diseases. N Engl J Med 2002;347(12):911-20. [PubMed: 12239261]

2. Ng SC, Shi HY, Hamidi N, et al. Worldwide incidence and prevalence of inflammatory bowel disease in the 21st century: a systematic review of population-based studies. Lancet 2018;390(10114):2769-78. [PubMed: 29050646]

3. Benchimol EI, Bernstein CN, Bitton A, et al. Trends in epidemiology of pediatric inflammatory bowel disease in Canada: distributed network analysis of multiple population-based provincial health administrative databases. Am J Gastroenterol 2017;112(7):1120-34. [PubMed: 28417994]

4. Chassaing B, Koren O, Goodrich JK, et al. Dietary emulsifiers impact the mouse gut microbiota promoting colitis and metabolic syndrome. Nature 2015;519(7541): 92-6. [PubMed: 25731162]

5. Chapel H, Lucas M, Lee M, et al. Common variable immunodeficiency disorders: division into distinct clinical phenotypes. Blood 2008;112(2):277-86. [PubMed: 18319398]

6. Ahmad T, Marshall S, Jewell D. Genotype-based phenotyping heralds a new taxonomy for inflammatory bowel disease. Curr Opin Gastroenterol 2003;19(4): 327-35. [PubMed: 15703573]

7. Stokkers PC, Reitsma PH, Tytgat GN, et al. HLA-DR and -DQ phenotypes in inflammatory bowel disease: a meta-analysis. Gut 1999;45(3):395-401. [PubMed: 10446108]

8. Silverberg MS, Mirea L, Bull SB, et al. A population- and family-based study of Canadian families reveals association of HLA DRB $1 * 0103$ with colonic involvement in inflammatory bowel disease. Inflamm Bowel Dis 2003;9(1):1-9. [PubMed: 12656131]

9. Peloquin JM, Goel G, Kong L, et al. Characterization of candidate genes in inflammatory bowel disease-associated risk loci. JCI Insight 2016;1(13):e87899. [PubMed: 27668286]

10. Holgersen K, Kutlu B, Fox B, et al. High-resolution gene expression profiling using RNA sequencing in patients with inflammatory bowel disease and in mouse models of colitis. J Crohns Colitis 2015;9(6):492-506. [PubMed: 25795566] 
11. Costello CM, Mah N, Hasler R, et al. Dissection of the inflammatory bowel disease transcriptome using genome-wide cDNA microarrays. PLoS Med 2005;2(8):e199. [PubMed: 16107186]

12. Koh TJ, DiPietro LA. Inflammation and wound healing: the role of the macrophage. Expert Rev Mol Med 2011;13:e23. [PubMed: 21740602]

13. Silva LC, Ortigosa LC, Benard G. Anti-TNF-alpha agents in the treatment of immune-mediated inflammatory diseases: mechanisms of action and pitfalls. Immunotherapy 2010;2(6):817-33. [PubMed: 21091114]

14. Lauritsen K, Laursen LS, Bukhave K, et al. Effects of topical 5-aminosalicylic acid and prednisolone on prostaglandin E2 and leukotriene B4 levels determined by equilibrium in vivo dialysis of rectum in relapsing ulcerative colitis. Gastroenterology 1986;91(4):837-44. [PubMed: 3017804]

15. Mackowiak PA. Brief history of antipyretic therapy. Clin Infect Dis 2000;31(Suppl 5):S154-6. [PubMed: 11113017]

16. Dieckgraefe BK, Stenson WF, Korzenik JR, et al. Analysis of mucosal gene expression in inflammatory bowel disease by parallel oligonucleotide arrays. Physiol Genomics 2000;4(1):1-11. [PubMed: 11074008]

17. Lawrance IC, Fiocchi C, Chakravarti S. Ulcerative colitis and Crohn's disease: distinctive gene expression profiles and novel susceptibility candidate genes. Hum Mol Genet 2001;10(5):445-56. [PubMed: 11181568]

18. Dooley TP, Curto EV, Reddy SP, et al. Regulation of gene expression in inflammatory bowel disease and correlation with IBD drugs: screening by DNA microarrays. Inflamm Bowel Dis 2004;10(1):1-14. [PubMed: 15058520]

19. Geboes K, Van Eyken P. Inflammatory bowel disease unclassified and indeterminate colitis: the role of the pathologist. J Clin Pathol 2009;62(3):201-5. [PubMed: 18952692]

20. Prenzel F, Uhlig HH. Frequency of indeterminate colitis in children and adults with IBD-a metaanalysis. J Crohns Colitis 2009;3(4):277-81. [PubMed: 21172287]

21. Heyman MB, Kirschner BS, Gold BD, et al. Children with early-onset inflammatory bowel disease (IBD): analysis of a pediatric IBD consortium registry. J Pediatr 2005;146(1):35-40. [PubMed: 15644819]

22. Carvalho RS, Abadom V, Dilworth HP, et al. Indeterminate colitis: a significant subgroup of pediatric IBD. Inflamm Bowel Dis 2006;12(4):258-62. [PubMed: 16633047]

23. Henriksen M, Jahnsen J, Lygren I, et al. Change of diagnosis during the first five years after onset of inflammatory bowel disease: results of a prospective follow-up study (the IBSEN Study). Scand J Gastroenterol 2006;41(9):1037-43. [PubMed: 16938716]

24. Feakins RM, British Society of G. Inflammatory bowel disease biopsies: updated British Society of Gastroenterology reporting guidelines. J Clin Pathol 2013; 66(12):1005-26. [PubMed: 23999270]

25. Schumacher G, Kollberg B, Sandstedt B. A prospective study of first attacks of inflammatory bowel disease and infectious colitis. Histologic course during the 1st year after presentation. Scand J Gastroenterol 1994;29(4):318-32. [PubMed: 8047806]

26. Tanaka M, Riddell RH, Saito H, et al. Morphologic criteria applicable to biopsy specimens for effective distinction of inflammatory bowel disease from other forms of colitis and of Crohn's disease from ulcerative colitis. Scand J Gastroenterol 1999;34(1):55-67. [PubMed: 10048734]

27. Lowichik A, Weinberg AG. A quantitative evaluation of mucosal eosinophils in the pediatric gastrointestinal tract. Mod Pathol 1996;9(2):110-4. [PubMed: 8657715]

28. Jyonouchi S, Forbes L, Ruchelli E, et al. Dyskeratosis congenita: a combined immunodeficiency with broad clinical spectrum - a single-center pediatric experience. Pediatr Allergy Immunol 2011;22(3):313-9. [PubMed: 21284747]

29. Schumacher G, Sandstedt B, Kollberg B. A prospective study of first attacks of inflammatory bowel disease and infectious colitis. Clinical findings and early diagnosis. Scand J Gastroenterol 1994;29(3):265-74. [PubMed: 8209188]

30. Surawicz CM, Belic L. Rectal biopsy helps to distinguish acute self-limited colitis from idiopathic inflammatory bowel disease. Gastroenterology 1984; 86(1):104-13. [PubMed: 6689653]

31. Jenkins D, Goodall A, Scott BB. Simple objective criteria for diagnosis of causes of acute diarrhoea on rectal biopsy. J Clin Pathol 1997;50(7):580-5. [PubMed: 9306939] 
32. Sicherer SH. Food protein-induced enterocolitis syndrome: clinical perspectives. J Pediatr Gastroenterol Nutr 2000;30(Suppl):S45-9. [PubMed: 10634298]

33. Leonard SA, Nowak-Wegrzyn A. Clinical diagnosis and management of food protein-induced enterocolitis syndrome. Curr Opin Pediatr 2012;24(6):739-45. [PubMed: 23042254]

34. Mane SK, Bahna SL. Clinical manifestations of food protein-induced enterocolitis syndrome. Curr Opin Allergy Clin Immunol 2014;14(3):217-21. [PubMed: 24651279]

35. Nowak-Wegrzyn A, Muraro A. Food protein-induced enterocolitis syndrome. Curr Opin Allergy Clin Immunol 2009;9(4):371-7. [PubMed: 19474706]

36. Orchard TR, Chua CN, Ahmad T, et al. Uveitis and erythema nodosum in inflammatory bowel disease: clinical features and the role of HLA genes. Gastroenterology 2002;123(3):714-8. [PubMed: 12198697]

37. Greuter T, Bertoldo F, Rechner R, et al. Extraintestinal manifestations of pediatric inflammatory bowel disease: prevalence, presentation, and anti-TNF treatment. J Pediatr Gastroenterol Nutr 2017;65(2):200-6. [PubMed: 27801751]

38. Jose FA, Garnett EA, Vittinghoff E, et al. Development of extraintestinal manifestations in pediatric patients with inflammatory bowel disease. Inflamm Bowel Dis 2009;15(1):63-8. [PubMed: 18626963]

39. Jose FA, Heyman MB. Extraintestinal manifestations of inflammatory bowel disease. J Pediatr Gastroenterol Nutr 2008;46(2):124-33. [PubMed: 18223370]

40. Duerr RH. The genetics of inflammatory bowel disease. Gastroenterol Clin North Am 2002;31(1): 63-76. [PubMed: 12122744]

41. Laharie D, Debeugny S, Peeters M, et al. Inflammatory bowel disease in spouses and their offspring. Gastroenterology 2001;120(4):816-9. [PubMed: 11231934]

42. Orholm M, Binder V, Sorensen TI, et al. Concordance of inflammatory bowel disease among Danish twins. Results of a nationwide study. Scand J Gastroenterol 2000;35(10):1075-81. [PubMed: 11099061]

43. Thompson NP, Driscoll R, Pounder RE, et al. Genetics versus environment in inflammatory bowel disease: results of a British twin study. BMJ 1996;312(7023): 95-6. [PubMed: 8555939]

44. Tysk C, Lindberg E, Jarnerot G, et al. Ulcerative colitis and Crohn's disease in an unselected population of monozygotic and dizygotic twins. A study of heritability and the influence of smoking. Gut 1988;29(7):990-6. [PubMed: 3396969]

45. Goyette P, Boucher G, Mallon D, et al. High-density mapping of the MHC identifies a shared role for HLA-DRB $1 * 01: 03$ in inflammatory bowel diseases and heterozygous advantage in ulcerative colitis. Nat Genet 2015;47(2):172-9. [PubMed: 25559196]

46. Lesage S, Zouali H, Cezard JP, et al. CARD15/NOD2 mutational analysis and genotype-phenotype correlation in 612 patients with inflammatory bowel disease. Am J Hum Genet 2002;70(4):84557. [PubMed: 11875755]

47. Li J, Moran T, Swanson E, et al. Regulation of IL-8 and IL-1beta expression in Crohn's disease associated NOD2/CARD15 mutations. Hum Mol Genet 2004; 13(16):1715-25. [PubMed: 15198989]

48. Economou M, Trikalinos TA, Loizou KT, et al. Differential effects of NOD2 variants on Crohn's disease risk and phenotype in diverse populations: a metaanalysis. Am J Gastroenterol 2004;99(12):2393-404. [PubMed: 15571588]

49. Cummings JR, Jewell DP. Clinical implications of inflammatory bowel disease genetics on phenotype. Inflamm Bowel Dis 2005;11(1):56-61. [PubMed: 15674114]

50. Duerr RH, Taylor KD, Brant SR, et al. A genome-wide association study identifies IL23R as an inflammatory bowel disease gene. Science 2006;314(5804):1461-3. [PubMed: 17068223]

51. Hampe J, Franke A, Rosenstiel P, et al. A genome-wide association scan of non-synonymous SNPs identifies a susceptibility variant for Crohn disease in ATG16L1. Nat Genet 2007;39(2):207-11. [PubMed: 17200669]

52. Rioux JD, Xavier RJ, Taylor KD, et al. Genome-wide association study identifies new susceptibility loci for Crohn disease and implicates autophagy in disease pathogenesis. Nat Genet 2007;39(5):596-604. [PubMed: 17435756] 
53. Levine A, Kugathasan S, Annese V, et al. Pediatric onset Crohn's colitis is characterized by genotype-dependent age-related susceptibility. Inflamm Bowel Dis 2007;13(12):1509-15. [PubMed: 17763471]

54. Henderson P, van Limbergen JE, Wilson DC, et al. Genetics of childhood-onset inflammatory bowel disease. Inflamm Bowel Dis 2011;17(1):346-61. [PubMed: 20839313]

55. Imielinski M, Baldassano RN, Griffiths A, et al. Common variants at five new loci associated with early-onset inflammatory bowel disease. Nat Genet 2009;41(12): 1335-40. [PubMed: 19915574]

56. Kugathasan S, Baldassano RN, Bradfield JP, et al. Loci on 20q13 and 21q22 are associated with pediatric-onset inflammatory bowel disease. Nat Genet 2008; 40(10):1211-5. [PubMed: 18758464]

57. Amre DK, Mack DR, Morgan K, et al. Investigation of reported associations between the 20q13 and 21q22 loci and pediatric-onset Crohn's disease in Canadian children. Am J Gastroenterol 2009;104(11):2824-8. [PubMed: 19623168]

58. Ostrowski J, Paziewska A, Lazowska I, et al. Genetic architecture differences between pediatric and adult-onset inflammatory bowel diseases in the Polish population. Sci Rep 2016;6:39831. [PubMed: 28008999]

59. Kelsen JR, Dawany N, Moran CJ, et al. Exome sequencing analysis reveals variants in primary immunodeficiency genes in patients with very early onset inflammatory bowel disease. Gastroenterology 2015;149(6):1415-24. [PubMed: 26193622]

60. Zhernakova A, van Diemen CC, Wijmenga C. Detecting shared pathogenesis from the shared genetics of immune-related diseases. Nat Rev Genet 2009; 10(1):43-55. [PubMed: 19092835]

61. Fischer A, Provot J, Jais JP, et al., Members of the CEREDIH French PID Study Group. Autoimmune and inflammatory manifestations occur frequently in patients with primary immunodeficiencies. J Allergy Clin Immunol 2017;140(5): 1388-93.e8. [PubMed: 28192146]

62. Bacchetta R, Notarangelo LD. Immunodeficiency with autoimmunity: beyond the paradox. Front Immunol 2013;4:77. [PubMed: 23630524]

63. Halfvarson J, Brislawn CJ, Lamendella R, et al. Dynamics of the human gut microbiome in inflammatory bowel disease. Nat Microbiol 2017;2:17004. [PubMed: 28191884]

64. Gupta N, Bostrom AG, Kirschner BS, et al. Presentation and disease course in early- compared to later-onset pediatric Crohn's disease. Am J Gastroenterol 2008;103(8):2092-8. [PubMed: 18796101]

65. Benchimol EI, Mack DR, Nguyen GC, et al. Incidence, outcomes, and health services burden of very early onset inflammatory bowel disease. Gastroenterology 2014;147(4):803-13.e7 [quiz: e814-5]. [PubMed: 24951840]

66. Oliva-Hemker M, Hutfless S, Al Kazzi ES, et al. Clinical presentation and five-year therapeutic management of very early-onset inflammatory bowel disease in a large North American cohort. J Pediatr 2015;167(3):527-32.e1-3. [PubMed: 25982142]

67. Glocker EO, Kotlarz D, Boztug K, et al. Inflammatory bowel disease and mutations affecting the interleukin-10 receptor. N Engl J Med 2009;361(21):2033-45. [PubMed: 19890111]

68. Uhlig HH, Schwerd T, Koletzko S, et al. The diagnostic approach to monogenic very early onset inflammatory bowel disease. Gastroenterology 2014;147(5): 990-1007.e3. [PubMed: 25058236]

69. Ashton JJ, Harden A, Beattie RM. Paediatric inflammatory bowel disease: improving early diagnosis. Arch Dis Child 2018;103(4):307-8. [PubMed: 29175974]

70. Meeths M, Entesarian M, Al-Herz W, et al. Spectrum of clinical presentations in familial hemophagocytic lymphohistiocytosis type 5 patients with mutations in STXBP2. Blood 2010;116(15):2635-43. [PubMed: 20558610]

71. Levine AP, Pontikos N, Schiff ER, et al. Genetic complexity of Crohn's disease in two large Ashkenazi Jewish families. Gastroenterology 2016;151(4):698-709. [PubMed: 27373512]

72. Speckmann C, Doerken S, Aiuti A, et al. A prospective study on the natural history of patients with profound combined immunodeficiency: an interim analysis. J Allergy Clin Immunol 2017;139(4): 1302-10.e4. [PubMed: 27658761]

73. Schwerd T, Bryant RV, Pandey S, et al. NOX1 loss-of-function genetic variants in patients with inflammatory bowel disease. Mucosal Immunol 2017;11:562-74. [PubMed: 29091079] 
74. Uzel G, Orange JS, Poliak N, et al. Complications of tumor necrosis factor-alpha blockade in chronic granulomatous disease-related colitis. Clin Infect Dis 2010; 51(12):1429-34. [PubMed: 21058909] 


\section{KEY POINTS}

- $\quad$ The epidemiology of inflammatory bowel disease (IBD) is changing with increased incidence and a younger age of onset recently.

- Approximately $20 \%$ of the very early onset IBD cohorts have an inherited primary immunodeficiency.

- The evaluation of patients can use a multimodal approach, but ultimately often relies on genetic sequencing 


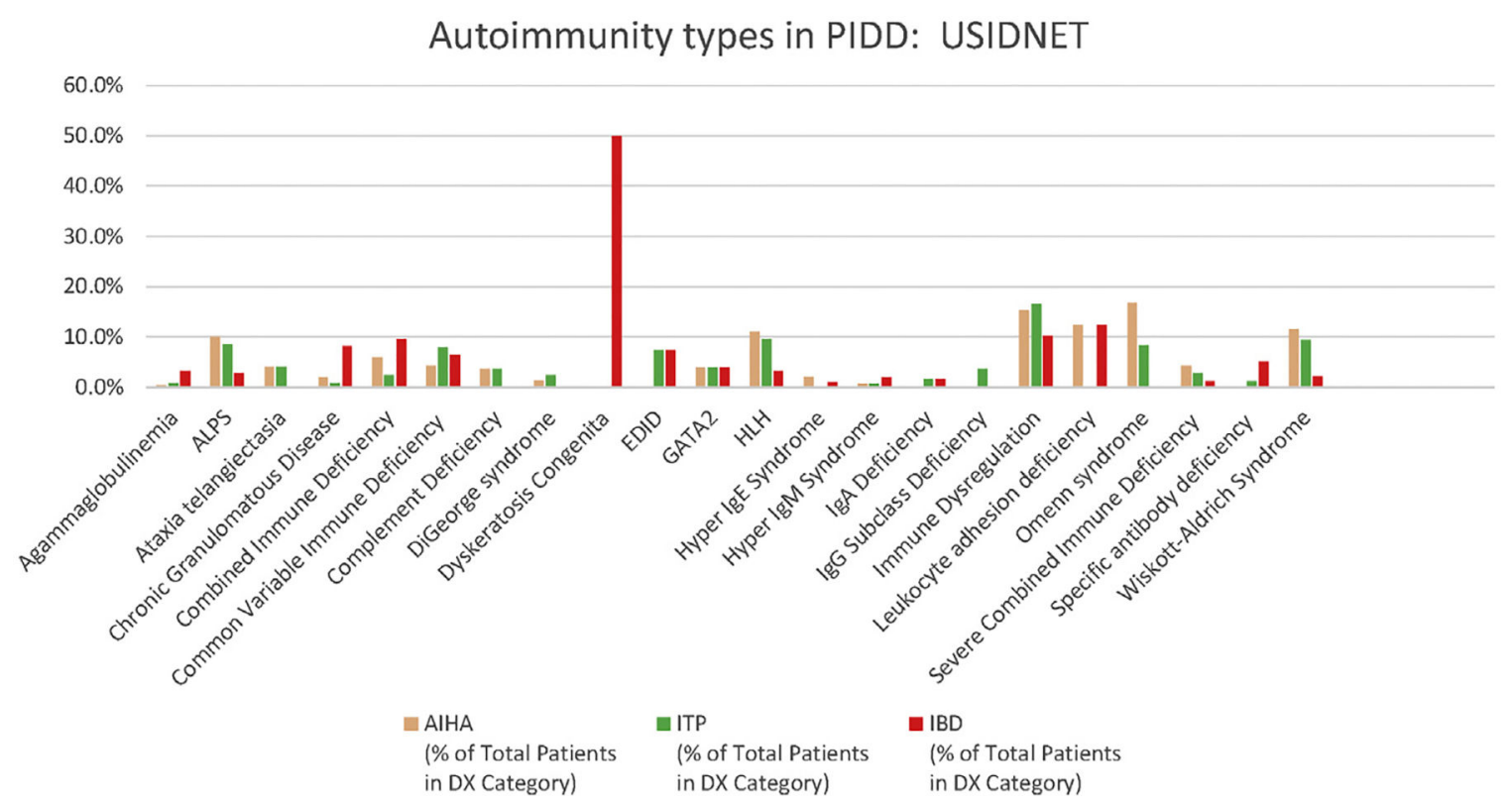

Fig. 1.

Autoimmune hemolytic anemia (AIHA), idiopathic thrombocytopenia purpura (ITP), and IBD frequencies in different primary immunodeficiencies (PIDDs). US Immunodeficiency Network (USIDNET) data were extracted and graphed to display the frequencies of the 3 different types of autoimmune diseases. ALPS, autoimmune lymphoproliferative syndrome; EDID, ectodermal dysplasia immunodeficiency; HLH, hemophagocytic lymphohistiocytosis. 


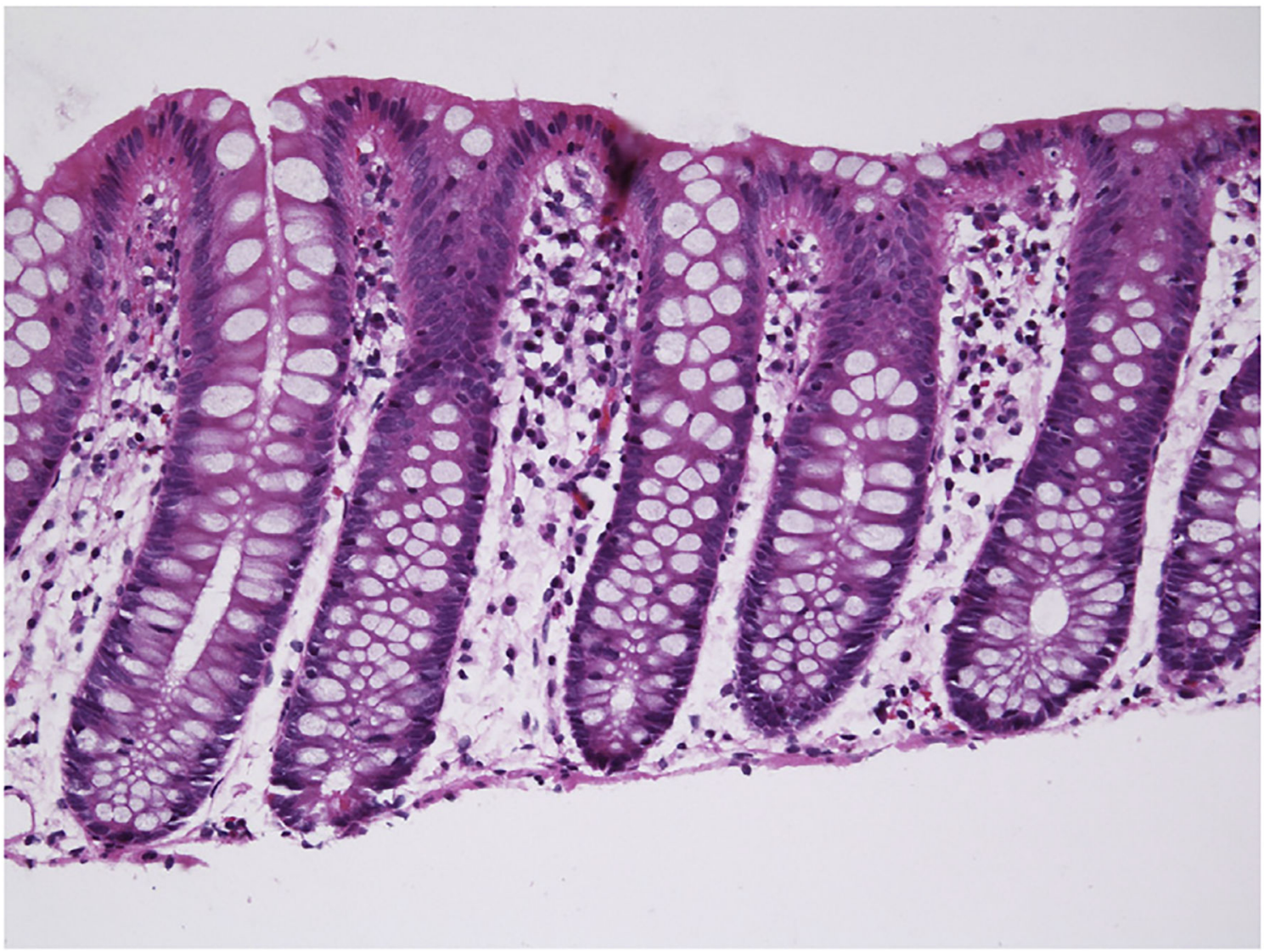

Fig. 2.

Normal colonic architecture with regular crypts. Clear goblet cells in the crypts are abundant. There are few cells between the crypts. Hematoxylin and eosin stain. Original magnification $\times 200$. 


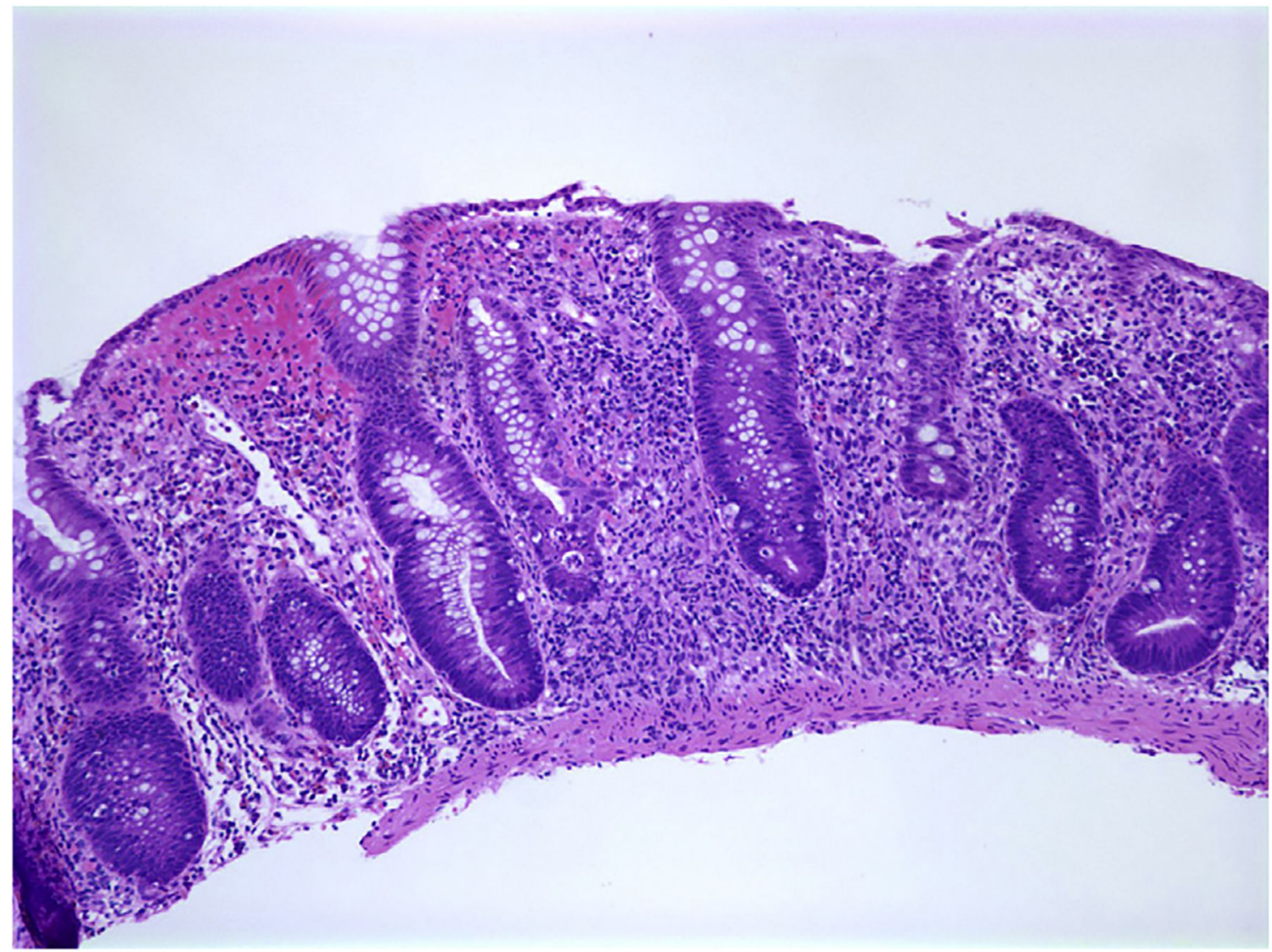

Fig. 3.

Shortened crypts with abundant inflammation in the lamina propria in a 2-year-old child with IBD. Crypts are irregular and goblet cells are diminished. Hematoxylin and eosin stain. Original magnification $\times 100$. 


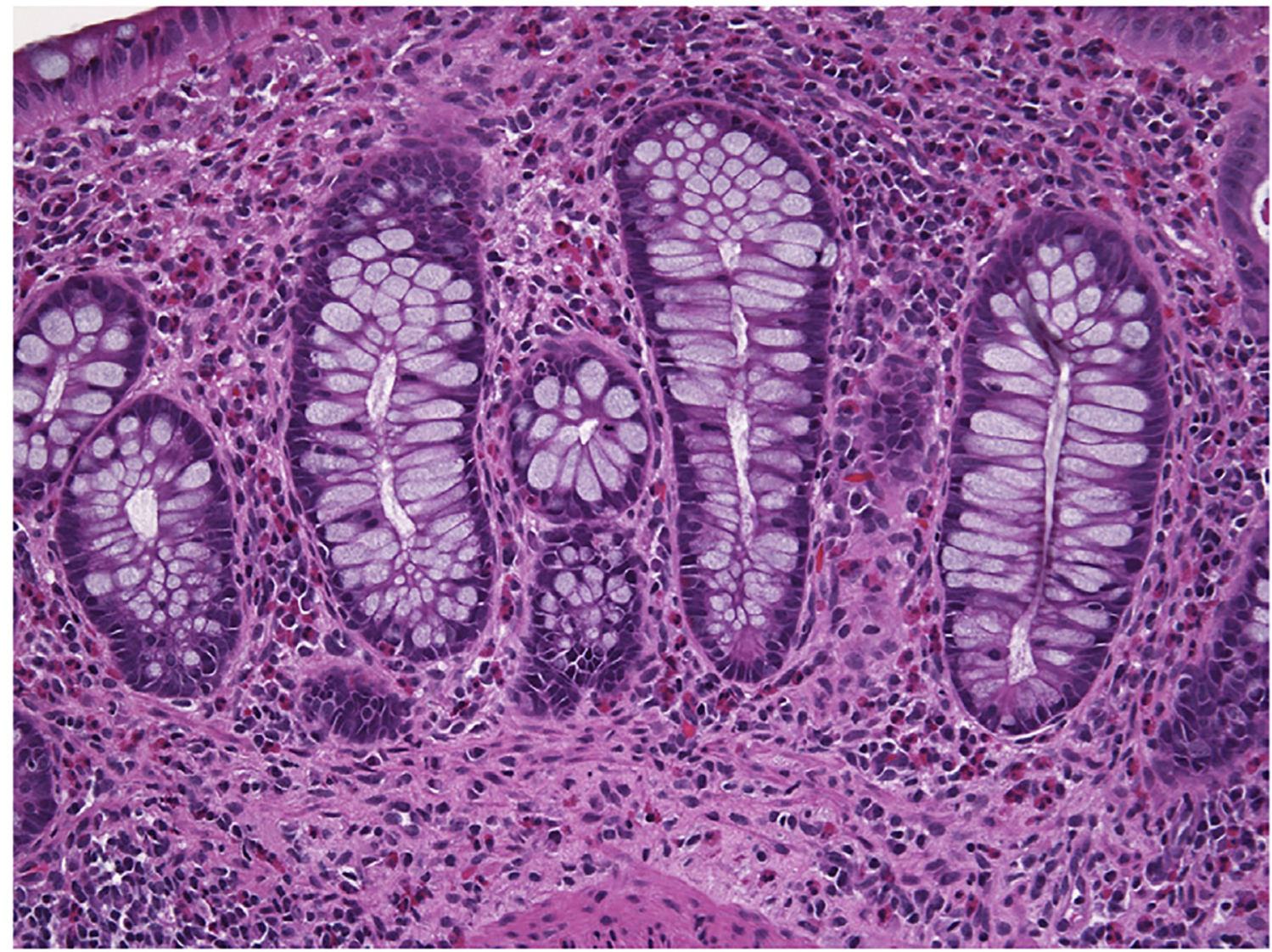

Fig. 4.

IBD in a 5-year-old child demonstrating an intense eosinophilic infiltrate in the lamina propria. Hematoxylin and eosin stain. Original magnification $\times 200$. 


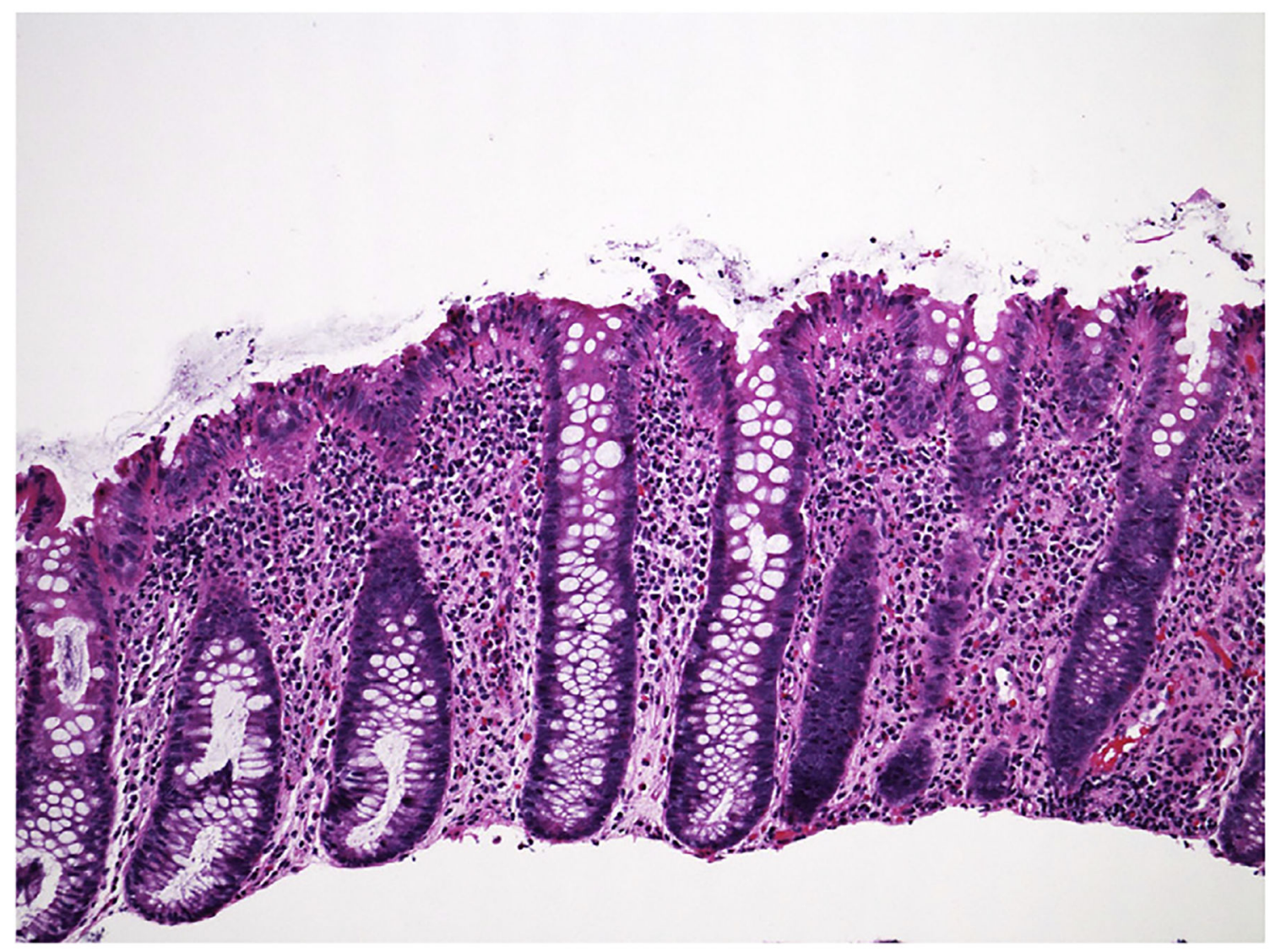

Fig. 5.

Bacterial gastroenteritis demonstrates normal crypt architecture and inflammation that is more pronounced at the luminal surface. Hematoxylin and eosin stain. Original magnification $\times 100$. 


\section{Table 1}

Comparison of Crohn disease and ulcerative colitis

\begin{tabular}{lll}
\hline Feature & Crohn Disease & Ulcerative Colitis \\
\hline Typical site of initiation & Terminal ileum & Rectum \\
\hline Pattern & Skip lesions & Extends proximally \\
\hline Layers affected & Transmural & Submucosa/mucosa \\
\hline Pathology & Granulomas, fissures & Crypt abscesses, pseudopolyps \\
\hline Complications & Fistulas, abscess & Hemorrhage, toxic megacolon \\
\hline Risk of colon cancer & + & ++ \\
\hline & $\begin{array}{l}\text { Fever, arthritis, pyoderma gangrenosa, Sweet } \\
\text { syndrome }\end{array}$ & $\begin{array}{l}\text { Hepatitis, sclerosing cholangitis, pyoderma gangrenosa, } \\
\text { Sweet syndrome, arthritis }\end{array}$
\end{tabular}




\section{Table 2}

\section{Differential diagnosis of colitis with chronic changes on pathology}

\begin{tabular}{|c|c|}
\hline Consideration & Notes \\
\hline Diversion proctocolitis & The excluded large bowel can show changes similar to IBD \\
\hline $\begin{array}{l}\text { Microscopic colitis (collagenous colitis or } \\
\text { lymphocytic colitis) }\end{array}$ & $\begin{array}{l}\text { These are not uncommon in primary immunodeficiency disorders but respond to alternative } \\
\text { therapies }\end{array}$ \\
\hline Diverticular colitis & Sigmoid disease usually in older adults with diverticulitis \\
\hline Radiation colitis & Fibrosis and vascular changes are characteristic in addition to chronic inflammation \\
\hline Ischemic colitis & The anatomic distribution is distinctive although the pathologic appearance can resemble IBD \\
\hline Graft vs host disease & $\begin{array}{l}\text { Pathologically is nearly indistinguishable from IBD, although apoptotic crypt epithelial cells are } \\
\text { prominent }\end{array}$ \\
\hline HIV-related colitis & HIV testing and extensive pathogen testing required \\
\hline Lymphogranuloma venereum & Testing for syphilis can diagnose this, which is typically seen in the setting of HIV \\
\hline Yersinia & Abundant granulomas with central necrosis \\
\hline Tuberculosis & Large granulomas \\
\hline Nonsteroidal anti-inflammatory use & Epithelial cell apoptosis prominent \\
\hline Mycophenolate mofetil & Pathology indistinguishable from IBD \\
\hline Behcet disease & Lymphoid aggregates \\
\hline Autoimmune enteropathy & Distinct autoantibodies; common in primary immunodeficiencies \\
\hline
\end{tabular}

Abbreviations: HIV, human immunodeficiency virus; IBD, inflammatory bowel disease. 
Table 3

Extraintestinal manifestations in adults

\begin{tabular}{lll}
\hline Finding & Crohn Disease, \% & Ulcerative Colitis, \% \\
\hline Erythema nodosum & 6 & 3 \\
\hline Pyoderma gangrenosum & 2 & 2 \\
\hline Skin tags & 37 & Low \\
\hline Orofacial granulomatosis & $<1$ & Low \\
\hline Oral ulcers & 10 & 4 \\
\hline Large joint arthritis & 15 & 8 \\
\hline Spondyloarthropathy & 6 & 2 \\
\hline Uveitis & 6 & 4 \\
\hline Sclerosing cholangitis & $<1$ & 3 \\
\hline Nephrolithiasis & 5 & 5 \\
\hline
\end{tabular}




\section{Table 4}

Extraintestinal manifestations in adults and children

\begin{tabular}{lll}
\hline Finding & Children, \% & Adults, $\%$ \\
\hline Growth failure & 30 & - \\
\hline Erythema nodosum & 4 & 2 \\
\hline Pyoderma gangrenosum & 2 & 1 \\
\hline Oral ulcers & 7 & 7.5 \\
\hline Arthritis & 20 & 7 \\
\hline Spondyloarthropathy & 5 & 1 \\
\hline Uveitis & 4 & 2 \\
\hline Sclerosing cholangitis & 2 & 1 \\
\hline
\end{tabular}




\section{Table 5}

Unique therapeutic options in patients with IBD due to monogenic primary immunodeficiencies

\begin{tabular}{ll}
\hline Gene Defect & Therapeutic Considerations \\
\hline$X I A P(\mathrm{X}$-linked lymphoproliferative disease) & HSCT, IL-18 binding protein study under way \\
\hline$C Y B B$ and other etiologies of CGD & IL-1 blockade; TNF inhibitors should not be used due to risk of fungal infections \\
\hline$I L 10$, IL10RA, IL10RB & HSCT \\
\hline$T T C 7 A$ & HSCT can be considered; however, success has been limited \\
\hline$L R B A$ & Abatacept, sirolimus, colchicine, HSCT \\
\hline$C T L A 4$ & Abatacept, sirolimus, HSCT \\
\hline$M E F V$ (Familial Mediterranean Fever) & IL-1 blockade, colchicine \\
\hline$N L R C 4$ & IL-18 binding protein \\
\hline
\end{tabular}

Abbreviations: HSCT, hematopoietic stem cell transplantation; IL, interleukin; TNF, tumor necrosis factor. 
Table 6

Monogenic causes of very early onset inflammatory bowel disease

\begin{tabular}{|c|c|c|}
\hline Gene Name & Disease Name & Category \\
\hline$A D A M 17$ & & Barrier dysfunction \\
\hline$A I C D A$ & Hyper IgM & Humoral \\
\hline$B T K$ & $\mathrm{X}$-linked agammaglobulinemia & Humoral \\
\hline$C D 4 O L G$ & X-linked Hyper IgM & Humoral \\
\hline CTLA4 & & Humoral \\
\hline$C Y B A$ & CGD & Neutrophil \\
\hline$C Y B B$ & CGD & Neutrophil \\
\hline$D K C 1$ & Dyskeratosis congenita & Telomeropathy \\
\hline DOCK8 & & Combined immunodeficiency \\
\hline FOXP3 & IPEX & Immune dysregulation \\
\hline HSP4 & Hermansky Pudlak & Immune dysregulation \\
\hline ICOS & & Immune dysregulation \\
\hline$I K B K G$ & NEMO & Combined immunodeficiency \\
\hline IL10 & & Immune dysregulation \\
\hline IL10RA & & Immune dysregulation \\
\hline IL10RB & & Immune dysregulation \\
\hline IL21 & & Humoral \\
\hline$I L 2 R A$ & & Combined immunodeficiency \\
\hline$I L 2 R B$ & & Combined immunodeficiency \\
\hline ITCH & & Immune dysregulation \\
\hline ITGB2 & LAD1 & Neurophil \\
\hline$L I G 4$ & & Combined immunodeficiency \\
\hline$L R B A$ & & Immune dysregulation \\
\hline$M E F V$ & Familial Mediterranean fever & Immune dysregulation \\
\hline$M V K$ & Hyper IgD syndrome & Immune dysregulation \\
\hline$N C F 2$ & CGD & Neutrophil \\
\hline NCF4 & CGD & Neutrophil \\
\hline NFAT5 & & Immune dysregulation \\
\hline$N L R C 4$ & & Immune dysregulation \\
\hline PIK3CD & & Immune dysregulation \\
\hline PIK3R1 & & Immune dysregulation \\
\hline$P L G C 2$ & & Immune dysregulation \\
\hline RTEL1 & Dyskeratosis congenita & Telomeropathy \\
\hline SKIV2L & THE syndrome & Combined immunodeficiency \\
\hline SLC7A4 & Lysinuric protein intolerance & Immune dysregulation \\
\hline STAT1 GOF & & Immune dysregulation \\
\hline STAT3 GOF & & Immune dysregulation \\
\hline
\end{tabular}

Immunol Allergy Clin North Am. Author manuscript; available in PMC 2020 January 10. 


\begin{tabular}{lll}
\hline Gene Name & Disease Name & Category \\
\hline STIM1 & & Combined immunodeficiency \\
\hline$S T X B P 2$ & HLH & Immune dysregulation \\
\hline$S T X B P 3$ & HLH & Immune dysregulation \\
\hline$T T C 7 A$ & Multiple intestinal atresia SCID & Combined immunodeficiency \\
\hline$T T C 37$ & THE syndrome & Combined immunodeficiency \\
\hline$W A S$ & Wiskott-Aldrich syndrome & Combined immunodeficiency \\
\hline$X I A P$ & XLP2 & Immune dysregulation \\
\hline
\end{tabular}

Exclusive of leaky severe combined immunodeficiency (SCID) and genetic causes of dyskeratosis congenita where inflammatory bowel disease has not been reported.

Abbreviations: CGD, chronic granulomatous disease; HLH, hemophagocytic lymphohistiocytosis; Ig, immunoglobulin; IPEX, immune dysregulation, polyendocrinopathy, X-linked syndrome; LAD, leukocyte adhesion deficiency; NEMO, NF-kappa-B essential modulator; THE, trichohepatic enteric; XLP, X-linked lymphoproliferative syndrome. 